\title{
DISCURSO E GOZO: PSICANÁLISE E SOCIEDADE
}

Maria Angélica Augusto de Mello Pisetta

Maria Angélica Augusto
de Mello Pisetta
Doutora e mestre
em Psicologia
pela UFRJ,
Especialista em
Psicologia Clínico-
Institucional pela
Uerj, Professora
de Psicologia
da Educação da
Faculdade de
Educação da UFF,
psicanalista.
Membro do Nupes/
UFF (Núcleo
de pesquisa,
subjetividade,
educação e cultura)

Maria Angélica Augusto

Doutora e mestre olog

Especialista em Psicologia ClínicoInstitucional pela Uerj, Professora de Psicologia da Educação da Faculdade de Educãão da UFF,

RESUMO: As mudanças no laço social contemporâneo propõem uma grande oportunidade de repensar o lugar e os fundamentos da psicanálise. Com uma multiplicidade sintomática, os fenômenos relativos ao corpo se apresentam fomentando a ampliação das discussões sobre o tema do gozo, articulado ao discurso. Abordaremos aqui esta questão recorrendo a uma breve contextualização histórica dos modos de contemplação do corpo, até a atualidade, quando podemos perceber mudanças substanciais no gozo relativo ao corpo. Exploraremos ainda as conceituações freudianas e lacanianas procurando debater as mudanças necessárias que a psicanálise é convocada a fazer ante as mutações do laço social.

Palavras-chave: Discurso, corpo, gozo, sociedade, Lacan.

ABSTRACT: Speech and joy: Psychoanalysis and Society. Changes in the contemporary social bond propose a great opportunity to rethink the place and the foundations of psychoanalysis. With a multitude of presentations, the phenomena related to the body foster the expansion of the discussions on the theme of joy, articulated to the speech. This issue is discussed here with a brief historical background on the forms of body contemplation, until the present, where we can see substantial changes in the enjoyment for the body. We further explore the Freudian and Lacanian concepts aiming to discuss the necessary changes that psychoanalysis is called to do in the face of changes in the social bond.

Keywords: Speech, body, enjoyment, society, Lacan.

DOI - http://dx.doi.org/10.1590/S1516-14982016000100002 
$\mathrm{V}$ ariados fenômenos relativos ao corpo se apresentam na atualidade e indicam uma abordagem pós-moderna na relação do homem com o corpo. Dentre estes fenômenos poderíamos citar a variedade de expressões do culto à imagem, fenômenos dos mais variados relativos ao corpo, como anorexias, bulimias, body-art, fenômenos psicossomáticos, dentre outros. Somos permanentemente desta forma confrontados com um modo de lidar com o corpo como expressão coletiva contemporânea. Como pode a psicanálise, valendo-se de sua abertura à política, responder às formas atuais que se manifestam de contemplação do corpo?

Para discutir a questão tomaremos, de início, a análise do atravessamento do discurso moderno da sociedade disciplinar em seu controle dos corpos, descrita por Foucault (1988) ao imperativo pós-moderno de autonomia e hedonismo, no que tange ao corpo, discutido por Lipovetsky (2009). Num segundo momento discutiremos a leitura psicanalítica de Freud e Lacan e alguns autores contemporâneos no que diz respeito ao conceito de corpo, para permitir a abordagem clínica deste intricado problema. O conceito de gozo e sua articulação com o corpo será pensada aqui a partir da concepção de facetas do gozo no ensino lacaniano, como evidencia Miller (2012).

Pretendemos, com isso, cotejar a visada clínica lacaniana aos impasses advindos da contemporânea apresentação do corpo na sociedade. Do mesmo modo, pretendemos discutir o que esta apresentação proporciona numa releitura da concepção de gozo e sua relação com o discurso.

\section{CORPO E SOCIEDADE}

Se, antes de qualquer coisa, "a existência é corporal” (LE BRETON, 2006, p.2), estamos advertidos da amplitude da questão da apreensão do corpo em qualquer época. Faz-se necessária uma análise histórica que privilegie a relação inescapável entre corpo e sociedade, corpo e discurso. Marroun e Vieira (2008) descrevem como o manejo social dos corpos em suas expressões podem ser relacionados aos modos de funcionamento social vigentes em cada época. Na Idade Média, a força social da Igreja e visão religiosa do homem como criatura divina, impunham uma relação em que o corpo poderia representar tanto a purificação da alma quanto seu sacrifício e punição, estando o corpo sempre submetido à alma. A socialização do corpo obedecia a estas normas.

Já no período renascentista (séculos XIV a XVI), o corpo passa a ser também mais relacionado ao belo, através da arte e passa a ser mais retratado; sendo apreciado em sua nudez. Segundo Marroun e Vieira (2008), há um incremento da beleza ligada à apreciação do corpo na modernidade, ressaltando o imaginário na abordagem de sua natureza, como podemos notar atualmente no imperativo de fotografar e exibir cada movimento corporal. Do mesmo modo, acentuam 
Marroun e Vieira (2008), o avanço do conhecimento de disciplinas científicas, como a anatomia e a fisiologia, ocorrido nos séculos XIX e XX, também teve grande influência na compreensão e expressão do corpo. Mas é a revolução industrial, com sua lógica do trabalho, que propicia uma leitura do corpo característica da modernidade.

O corpo-máquina (FOUCAULT, 1988) pode ser compreendido como apreensão psicossocial e como resposta subjetiva à necessidade social da força de trabalho para o desenvolvimento tecnológico durante a revolução industrial. Assim, surge a sociedade disciplinar moderna, que evidencia o poder social da modernidade exercido através do controle do corpo em sua sexualidade e rebeldia. O modelo escolar da sala de aula desponta como o paradigma moderno da disciplinarização dos corpos. Assim, “a disciplina fabrica corpos submissos e exercitados, corpos dóceis. A disciplina aumenta as forças do corpo (em termos econômicos de utilidade) e diminui estas mesmas forças (em termos políticos de obediência)" (FOUCAULT, 1988, p.127).

Estes métodos, já existentes, tornam-se, no século XVIII, formas gerais de dominação e como tal são manifestações distintas da escravidão — pela apropriação do corpo do outro, custosa e violenta; distintas da domesticidade — pela dominação constante do capricho do mestre; distintas ainda da vassalidade pela relação de submissão altamente codificada e, por último, distintas do ascetismo - na realização das renúncias e domínio de cada um sobre seu próprio corpo (idem). Temos aí a resposta moderna de um corpo subjetivamente que se apresenta submetido, controlado, transformado e aperfeiçoado. Mesmo aí, contudo, como salienta Roudinesco (2003), a histeria se apresentou como uma resposta transgressora a esse imperativo de domínio do corpo.

Para Lipovetsky (1983), a contemporaneidade, a partir do século XX, testemunha vínculos sociais e expressões relacionais característicos. São muitas transformações em curso, e surge constantemente uma pluralidade de vínculos. A individualidade crescente é marcada pela tendência à autonomia e socialmente testemunhamos um avanço científico e tecnológico que se manifesta nas relações. Segundo o autor, “a velocidade com que o avanço da ciência se estabeleceu desenhou uma nova cartografia contemporânea desenhada pela transitoriedade e pela efemeridade” (LIPOVETSKY, 1983, p.230). Na mesma esteira, o lugar social do corpo experimenta mudanças consideráveis, passando a ser o corpo, sua imagem e seu manejo, objetos de consumo e fontes de promessas de satisfação ilimitada. A exploração e utilização do corpo não servem mais apenas ao domínio de sua força em nome de um aproveitamento produtivo, mas a um gozo ilimitado, estético e social. Assim, o cuidado e o consumo do corpo passam a ser vistos como indicativos de valor e destaque social, como bem salienta Freire Costa (2004). Assim, atualmente não basta mais modificar o corpo com 
cirurgias plásticas ou maratonas de exercícios, é necessário exibi-lo. Em 1925, no livro A rebelião das massas, Ortega Y Gasset (1961) já advertia que o corpo seria a grande ilusão dos séculos XX e XXI. Nestes termos, podemos constatar que as influências estéticas massivas podem ser mais ansiogênicas e desestabilizantes do que as modernas exigências sexuais ligadas à procriação ou à uniformização (EHRENBERG, 2004).

É imprudente abordar a problemática social do corpo, sem atentar para a relação entre este último e as determinações atuais de nossa cultura. Ehrenberg (2004), em sua pesquisa sociológica sobre a depressão, reflete que passamos da disciplina como imperativo social moderno para a autonomia, o que, como uma linguagem, contribui na produção de novas formas de subjetividade. Para o autor, a ênfase da psicanálise freudiana no sintoma como retorno do recalcamento se balizava na sociedade disciplinar, com normas e regras bem definidas e defendidas pelas instituições sociais, representadas, em última instância, pelo Estado. O autor também sublinha que ainda é a psicanálise a possibilidade pós-moderna de incentivo à subjetividade, em tempos de impotência e desorientação subjetivas. Com a relativização do poder social do Estado e da coletividade, em favor do individualismo, o que pode a psicanálise nos tempos atuais?

\section{CORPO, DISCURSO E GOZO}

Abordar o conceito e a problemática do corpo na psicanálise requer uma elaboração que retorne à atenção freudiana às manifestações do corpo na clínica e às dificuldades teóricas de apreensão do mesmo na representação da imagem de superfície corporal (1923/1980). Nesse retorno, salientamos, a seguir, algumas contribuições freudianas.

Por um lado, temos a teorização de que o corpo, em sua parcialidade, pode ser abordado como substituto, numa vertente representacional, pelo sintoma conversivo. Assim, como destino da pulsão (1915/1980), através do recalcamento, um tique vocálico, uma afonia, uma paralisação de membro, pode ser "ouvida” pelo analista e remontada pela associação à ideia confinada "no esconderijo da libido" (FREUD, 1914/1980) pelo processo do recalcamento. Assim, uma parte do corpo, o pensamento ou o objeto (FREUD, 1926/1980) podem ser requeridos para a expressão sintomática produzida pelo recalcamento no encontro com a angústia de castração. Do mesmo modo, a concepção do eu no trabalho freudiano passa pela representação do corpo e sua possível dialetização. É deste modo que o autor sublinha que o eu é projeção de superfície corporal em 1923 e destaca ainda em 1933 a importância da percepção para a produção desta instância de superfície que faz fronteira tanto ao que é “terra estrangeira exterior”, 
o mundo externo, quanto ao que é “terra estrangeira interior”, domínio da pulsão (FREUD, 1933/1980).

Se por um lado a representação pôde alimentar a psicanálise nascente, por outro, temos toda uma demonstração freudiana do corpo em sua vertente pulsional que, em parte, não se inscreve, nem se representa e insiste, sem se fazer representar. É assim, por exemplo, que o autor ressalta, em sua classificação inovadora das neuroses, a presença de um grupo, por ele descrito como neuroses atuais que não podem ser pensadas no registro do recalcamento:

“a prisão de ventre, as dores de cabeça, o mal-estar do chamado neurastênico não podem ser remontados histórica ou simbolicamente, a experiências operantes e não podem ser compreendidos como substituto da satisfação sexual ou como conciliação entre impulsos instintuais opostos, como é o caso dos sintomas psiconeuróticos." (FREUD, 1896/1980, p.210)

Nesta citação, podemos observar que ainda que envolvido na produção de um método de abordagem e conceituação aos sintomas substitutivos e portanto simbólicos, o autor não se deixa iludir em relação aos limites desse trabalho. Sua referência ao conceito de pulsão como "medida de exigência de trabalho feita à mente em função de sua ligação com o corpo” (1915/1980, p.142), também dá abertura para a compreensão de um trabalho sempre inacabado na relação do sujeito ao seu corpo. Outra referência importante é sua abordagem do prazer de órgão na hipocondria (1912/1980) mostrando como o destino da pulsão pode se apresentar à análise sob um viés diferente que os da representação, fundamento da associação livre e da interpretação, que consagraram um lugar para a psicanálise na modernidade.

É com Lacan que a abordagem do corpo na constituição do sujeito propõe uma maior abertura às questões políticas da pós-modernidade, sobretudo na relação que o autor estabelece entre o gozo e o corpo. É importante destacar que para Lacan (1992), em sua leitura discursiva do gozo, os laços sociais são laços discursivos e, como tal, as relações de linguagem entre as pessoas definem diferentes maneiras de lida com o corpo e com o gozo. Assim, os discursos que regem as relações sociais situam as relações intersubjetivas. É nessa vertente que entendemos que o inconsciente é a política (LACAN apud MILLER, 2011), numa indicação de que o sujeito se constitui na incessante tensão em relação àquilo que o Outro lhe propõe e o quanto ele pode se separar disso. Além da referência ao Outro no laço discursivo, é indispensável na abordagem do corpo em Lacan, a análise do conceito de gozo. Ela, no entanto, é complexa e a situaremos no que segue.

Viltard (1996, p.221) destaca que o gozo demarca uma relação do sujeito com a linguagem, já anunciada por Freud em seu texto Os chistes e sua relação com 
o inconsciente, quando ele ressalta que a satisfação, encontrada através do chiste, é proporcionada por sua comunicação a um interlocutor. Assim, nos diz Freud, “Um chiste deve ser contado a alguém (...) também no caso do cômico, contá-lo a mais alguém produz prazer” (FREUD, 1905/1980, p.166). E discute aí não apenas a exigência da comunicação do chiste para a obtenção de um gozo (Genuss), mas a contingência desta satisfação, dependendo do modo como o chiste é contado e ainda da reação do ouvinte. Assim, "o gozo é visado num esforço de reencontro" (VILTAR, 1996, p.221), mas neste reencontro o sujeito encontra sempre novamente uma perda.

\section{SIGNIFICANTE E GOZO}

Miller (2012) acentua que o conceito de gozo em Lacan pode ser pensado como uma doutrina, que admite seis ordenamentos distintos, seis paradigmas. Assim não haveria uma teoria única do gozo no ensino lacaniano. As definições acompanham o avanço de suas especulações, suportando, a cada virada teórica, uma definição distinta.

Um primeiro paradigma se refere à imaginarização do gozo (que compreende os seminário iniciais de Lacan, até 1958), quando o gozo é tomado como algo alcançável no sentido do que se produz na comunicação intersubjetiva, na relação de sujeito a sujeito, se localizando no imaginário. A segunda perspectiva teórica do gozo é denominada por Miller de significantização (signifiantisation), que pode ser observada mais claramente no ensino lacaniano da mesma época que o anterior, em especial nos anos de 1958 e 1959, representando, deste modo, já uma elaboração do primeiro paradigma. A articulação simbólica agora ordena o campo do imaginário. Assim, o gozo aqui aparece especialmente pelo efeito da sublimação (MILLER, 2012, p.90).

Na terceira ordenação do gozo, denominada por Miller como gozo impossível, o gozo é pensado como algo que não está mais, nem no imaginário, nem no simbólico, mas que só é possível mediante uma transgressão, e é como barreira ao gozo que se produz toda a simbolização. Esta concepção do gozo pode ser observada em O seminário, livro 7: A ética da psicanálise (LACAN, 1959/1988).

A postulação de um gozo normal ou fragmentário é encontrada no seminário de 1964, no qual o simbólico e o gozo retomam suas relações teóricas. Assim, o encontro com os objetos $a,{ }^{1} 1$, por exemplo o carretel do fort-da, possibilita esse gozo, mediante a premência da palavra.

\footnotetext{
${ }^{1} \mathrm{O}$ conceito de objeto a não responde por uma única formulação na obra de Lacan. Desde o seminário sobre a angústia, no qual ele traça marcações deste conceito, as definições transmitem o desdobramento de seu ensino. Aqui, temos: "Na medida em que esse objeto a designa precisamente o que, dos efeitos do discurso, se apresenta como o mais opaco, há
} 
Como quinto paradigma temos o gozo discursivo, nos anos de 1969-70 a 1972. O gozo, agora interditado, vem a ser suplementado pelo objeto a, denominado mais de gozar. A ordem simbólica estabelece uma correlação com o gozo, ilustrada pela relação entre o significante e o gozo, que se apresenta na repetição (MILLER, 2012). Como teorização final do gozo, Miller propõe o paradigma da não-relação, situado em O seminário, livro 20: Mais, ainda (1972/1985) quando há uma reviravolta no ensino lacaniano, pois se teoriza uma não-relação entre o significante e o gozo.

Privilegiaremos aqui a análise do gozo discursivo, articuladora de nossa discussão sobre o corpo e o Outro. Lembremos que em uma nota de revisão a Função e campo da palavra e da linguagem (1953/1966), Lacan retoma Além do princípio do prazer para destacar que o limite intrínseco à vida, definido por Freud (1920/1980) como pulsão de morte, e atuante na compulsão à repetição, não representa o retorno de um passado natural, nem tampouco de um passado histórico, mas, sobretudo, um limite interno à própria linguagem, que está sempre lá. Pois bem, aqui ele nos diz que "o caminho para a morte nada mais é do que aquilo que se chama gozo" (LACAN, 1992, p.16). Entendemos que caminho para a morte aqui é uma forma de denominação da pulsão de morte freudiana, que neste momento teórico de Lacan pode ser conceituado como um limite interno à linguagem, atravessado por ela e representado pelo significante. Vemos assim certa confluência entre os conceitos de tiquê, encontro do real e gozo. Porém, o encontro do real, pensado através do conceito de tiquê, excluía toda sorte de saber. Nesta formulação, tal encontro se dá ali mesmo onde o significante representa o gozo.

Se o caminho para a morte (limite do simbólico) era visto antes como a aproximação de um núcleo de real, alheio a todo sentido, agora ele é intrínseco a toda representação significante, não sendo mais concebido como algo apartado da linguagem, algo a que ela não tem acesso.

Assim, o que Lacan promove é também uma releitura da função do significante, tendo em vista uma relação inicial, agora concebida, entre saber e gozo. Em Produção dos quatro discursos, lição inaugural do seminário de 1969, Lacan destaca as relações entre a noção de gozo e a de sujeito, a partir dos discursos. O sujeito é pensado como o que resulta da operação significante. O limite a que a repetição se referia antes é aqui denominado gozo: “A repetição tem certa relação com aquilo que, desse saber, é o limite — e que se chama gozo” (LACAN, 1992, p.13). O que antes era apontado por Lacan como um limite à simbolização, encontro do real, é agora designado gozo. Assim, o que Lacan promove nesse seminário

muitíssimo tempo desconhecido, e, no entanto essencial. Trata-se do efeito de discurso que é efeito de rechaço" (LACAN, 1992, p.40). Por esta definição percebemos que o objeto a também comunga desta intimidade entre saber e gozo, sendo pensado, a rigor, na confluência destes dois registros. É efeito de discurso e também o que desse discurso resulta incógnito. 
é também uma releitura da função do significante, tendo em vista uma relação original, agora concebida, entre saber e gozo.

Miller propõe a nomeação de gozo discursivo à relação que Lacan demonstra entre o saber e o gozo, a partir da qual o saber (os significantes) e o gozo resguardam uma relação de origem. A definição de saber aqui é consoante com o saber inconsciente freudiano; na leitura lacaniana, ao que é relativo ao significante. O que isso representaria?

Miller (2012) destaca que no ensino precedente de Lacan a esse seminário (1992), sempre se nota uma divisão entre o saber (a estrutura do significante, o campo do Outro, o surgimento do sujeito) e o que escaparia a isso. A noção de gozo no seio mesmo do discurso introduz uma relação de origem entre estas duas esferas: "isso consiste em deduzir esta falta, esse buraco do gozo, a partir do significante” (MILLER, 1998/1999, p.219). Assim, porque o saber é visto como meio de gozo, o significante não é apartado do gozo e sua repetição demarca um acesso ao gozo, no entanto, sempre falho e incompleto.

Miller discute ainda que a definição lacaniana do significante ("um significante é aquilo que representa um sujeito para outro significante”, LACAN, 1960/1998, p.833) nos remete sempre a uma exclusão do gozo, quando temos um sujeito que está referido essencialmente ao significante. Para Miller (2012), a postulação lacaniana de um gozo no saber comporta a seguinte formulação: "o significante representa um gozo para um outro significante” (MILLER, 2012, p.96). O gozo agora partilha da cadeia simbólica, sendo-lhe essencial, e podemos até supor, acompanhando o autor, que é o significante que permite o gozo e vice-versa.

Por outro lado, "ao representar o gozo, o significante o faz faltar" (idem, MILLER, 2012, p.96), e não podemos mais falar de um gozo absoluto, nem natural. O significante faz faltar o gozo, como também faz faltar o sujeito, pela representação. Na primeira fórmula temos uma ênfase na relação do sujeito ao significante, e na circularidade da definição dos significantes, sendo ele definido a partir de si mesmo. Como acentua Miller, o significante é definido "pelo significante, através do sujeito” (idem, p.97). Um significante, assim, nunca está sozinho, participa de um sistema definidor: a cadeia. Logicamente, a cadeia nos remete à repetição, engendrada pela própria circulação dos significantes (do saber), mas aqui também ao gozo do corpo.

Desse modo, a causa da repetição, no âmbito significante, se traduz pela depuração da fórmula "um significante representa um sujeito para um outro significante” (LACAN, 1960/1998, p.833). Desse modo, logicamente, há representação do sujeito e também ausência de representação, que desemboca na repetição. Isso nos remete a um significante que não representa o sujeito e à ausência de um significante que o represente. Situa-se um significante que não está no conjunto dos significantes que representam um sujeito frente a outro 
significante. Isso instaura, na cadeia significante, uma não-representação, a ausência de um significante que represente um sujeito. Seria esse um lugar para o corpo (não-representado) no próprio saber do sujeito?

Nesta perspectiva, a repetição se produz pela ausência de um significante que traga em si a significação do que é o sujeito. Pela falta deste significante chegamos à falta do sujeito, que, por ser representado, não está lá. Essa falta do sujeito se apresenta tanto quanto sua representação. O irrepresentável e o representável do sujeito são veiculados pelo significante e engendram a repetição.

Vemos assim que não é apenas o sujeito que falta, por ser representado. Neste campo do saber que o significante introduz, no gozo discursivo, o gozo está interditado, porque representado. Todavia, esclarece Miller (2012, p.97), “ao mesmo tempo em que o gozo é interdito, ele pode ser dito nas entrelinhas". Algo resta do gozo, porque representado pelo significante. O gozo resta como objeto perdido através do significante na produção da cadeia. Podemos, assim afirmar com Lacan: o saber é meio de gozo (LACAN, 1992).

Miller ressalta ainda que a decorrência lógica deste paradigma é certa semelhança conceitual entre gozo e sujeito. Sim, pois, se o sujeito é aquilo que é representado de um significante a outro, e se o gozo pode aqui também ser representado, aparecendo como falta na construção da cadeia significante, há correspondência lógica entre eles. Essa semelhança conceitual implica uma nova compreensão da relação do sujeito com o seu corpo, do qual o sujeito goza; relação esta que passa pela representação de forma a fazer faltar o próprio sujeito.

A própria formulação dos discursos, como permutações circulares, das quais o gozo não está excluído (representado pelo objeto a) nos remete a essa releitura do significante que Lacan empreende aqui. Na circulação dos significantes, o objeto a pode até servir como um significante, como nos indica Miller (2012), pois também se ordena como significante, pois está situado ao lado dos indicativos da linguagem: S barrado, S1 e S2, articulando-se junto a eles, para formalização dos discursos, e ainda, no discurso do analista, chega a ocupar o lugar de agente. Desta forma, o gozo está representado, não todo, porém presente. Ele é acessível pela via da circulação dos significantes.

Lacan esclarece que ocupar-se da estrutura do significante (que aqui entendemos como essencialmente gozo representado) se justifica por um retorno a Freud, que de início demonstrou que o inconsciente é o registro de um desejo (LACAN, 1992, p.43). A repetição, entendida por Freud num viés edípico (como atuação das relações primitivas do sujeito, por exemplo, com o analista), conta a história desse desejo. Lacan, porém, vai além, dizendo que não é apenas o significante que ela exibe em seu movimento circular, mas sobretudo o gozo. Em assim sendo, declara: "É o gozo (...) que necessita a repetição” (idem, p.43). Define então a repetição como uma "dialética do gozo”, pela qual a busca do 
gozo força o sujeito na trilha dos caminhos familiares, na conservação de estados prévios.

Se a representação, através dos significantes, aparta o corpo de uma pretensa natureza, o que ela não abarca demarca uma parcela de gozo, que resiste a se fazer codificar no mesmo movimento da repetição significante. As manifestações gozosas no corpo demonstram a presença do objeto a, resíduo da tentativa de simbolizar o real e convocam o analista a um trabalho distinto daquele empreendido com a representação deste mesmo corpo. Para além do imaginário no estádio do espelho e do simbólico atrelado aos sintomas neuróticos, a vertente real do corpo se manifesta na clínica questionando o lugar da psicanálise nos laços sociais: "Reconduzir a experiência psicanalítica à fala e à linguagem assim como a seus fundamentos, interessa à sua técnica” (LACAN, 1953/1966, p.153).

Como vimos, na análise do gozo discursivo, o gozo é reduzido, à medida que é articulado ao funcionamento da cadeia significante. No entanto, embora seja representado, tal representação não pode esgotá-lo, deixando um resto que se manifesta sempre na repetição. Assim, o sujeito tem acesso, mediante a repetição, a um pouco de gozo, e assim, ao gozo do corpo. Da mesma forma, o conceito de objeto a também se altera, já que ele passa a ser perdido e recuperado na própria elaboração significante e não mais visto como um resto, caído do corpo. Como pensar esta articulação teórica no que diz respeito ao corpo na atualidade?

É reconhecidamente uma preocupação atual da psicanálise repensar sua prática no enfrentamento dos novos sintomas e na discussão dos fenômenos socioculturais de seu tempo. Esta atualização da posição da psicanálise também indica a necessidade da psicanálise se reinserir no laço social através da presença do analista nos mais diversos espaços públicos, nos quais a psicanálise é, por excelência, psicanálise em extensão (LACAN, 2003). Para Laia (2010), “precisamos incluir em nossa prática os meios que visam lidar com os efeitos do discurso que envolvem uma reorientação na política” (LAIA, 2010, p.2).

Freud (1912/1980) já indicava que o trabalho com a elaboração poderia ajudar os neurastênicos a produzirem uma leitura que os auxiliasse com seus sofrimentos. Tratar-se-ia, no enfrentamento do que se apresenta na contramão da representação, de repetir o método da associação livre e da elaboração, ponto de apoio do tratamento psicanalítico das neuroses?

Recalcati (2009) assevera que é necessário, diante da modificação do laço social com a consequente queda dos ideais que testemunhamos na atualidade, proporcionarmos uma retificação do Outro. Assim, retoma a articulação lacaniana do tratamento possível da psicose e lembra que todo tratamento se baseia na possibilidade de uma operação do significante do Nome do Pai. A diferença fundamental indicada pelo autor é que a retificação do Outro funcionaria, em relação às manifestações dos sintomas contemporâneos, como forma de entrada 
no dispositivo analítico; enquanto que na clínica da psicose ela coincide com o próprio tratamento.

A posição do analista está, deste modo, profundamente questionada com os novos sintomas que se apresentam nas relações sociais. Não se trata mais apenas de proporcionar ao sujeito uma transferência em ato de suas produções inconscientes, mas, antes, de reconsiderar sua posição na transferência - e o próprio conceito de transferência. Funtes \& Miller (2008) destacam ainda que diante da presença encarnada do objeto a, como podemos testemunhar nas passagens ao ato e nos fenômenos ligados ao corpo não dialetizado no sintoma, é preciso recorrer a um trabalho semelhante àquele utilizado com o trauma, que consiste em isolar o que resiste à inscrição numa cadeia significante. Ou seja, o que se apresenta sem qualquer correlato subjetivo - como é comum nas queixas que incluem um corpo não representado sintomaticamente - pode ceder ao trabalho de ser um significante, ainda que desatrelado - no interior de uma cadeia associativa.

A clínica atual reserva ao analista advertido das mudanças no laço social contemporâneo uma grande oportunidade de repensar seu lugar e os fundamentos da psicanálise. Com uma multiplicidade sintomática, os fenômenos relativos ao corpo se apresentam fomentando a ampliação dos conceitos e da inserção da psicanálise na sociedade.

Nesta oportunidade, abordamos a questão recorrendo a uma breve contextualização histórica dos modos de contemplação do corpo, até a atualidade, quando podemos perceber mudanças substanciais no gozo relativo ao corpo. Exploramos ainda as conceituações freudianas e lacanianas procurando debater as mudanças necessárias que a psicanálise é convocada a fazer ante as mutações do laço social.

A abordagem do corpo e suas manifestações requer um analista advertido das mutações no discurso social e nos laços procedentes deste. Afinal, como salientou Lacan, para estar à altura de seu trabalho, um analista precisa contemplar o espírito de seu tempo (LACAN, 1953/1966).

Recebido em 12/12/2012. Aprovado em 18/2/2013. 


\section{REFERÊNCIAS}

AGUIAR, I. (2007) "Possibilidades da escuta psicanalítica da fadiga de si: um estudo sobre a teoria freudiana do sofrimento psíquico". Dissertação de mestrado, Programa de Pós-Graduação em Psicologia, Instituto de Psicologia da Unifor.

ARIÉS, P. (1978). História social da criança e da família. Rio de Janeiro: Jorge Zahar.

EHRENBERG, A. (2004) Depressão, doença da autonomia? Entrevista de Alain Ehrenberg a Michel Botbol. Ágora v.7, n.1. Disponível em: http://www.scielo.br/scielo.php?script=sci_arttext\&pid $=$ S1516-14982004000100009. Acesso em 17/12/2015.

FOUCAULT, M. (1988) Vigiar e punir. Petrópolis: Vozes.

FUENTES, A. (2008) “Minna: O fio da vida”, in MILLER, J. Efeitos terapêuticos rápidos em psicanálise. Belo Horizonte: Escola Brasileira de Psicanálise/ Scriptum Livros.

FREIRE COSTA, J. (2004) O vestígio e a aura: corpo e consumismo na moral do espetáculo. Rio de Janeiro: Garamond.

FREUD, S.(1980) Edição standard das obras completas de Sigmund Freud. Rio de Janeiro: Imago.

(1896) "Novos comentários sobre as neuropsicoses de defesa”, v.III, p.187-216.

(1905) "Os chistes e sua relação com o inconsciente", v.VIII, p.267275.

(1912) “A dinâmica da transferência”, v.XII, p.131-146.

(1914) "Recordar, repetir e elaborar”, v.XII, p.193-207.

(1915) “Os instintos e suas vicissitudes”, v.XIV. p.137-168.

(1920) “Além do princípio do prazer”, v.XVIII, p.17-90.

(1921) “Psicologia de grupo e a análise do eu”, v.XVIII, p.91-184.

(1923) “O ego e o id”, v.XIX. p.23-90.

(1926) “Inibições, sintomas e ansiedade”, V.XX. p.107-198.

(1930) “O mal-estar na civilização”, v.XXI, p.81-178.

(1933) "Novas conferências introdutórias sobre psicanálise”, v.XXII, p.15-228.

LACAN, J. (1953/1966) “Função de campo da fala e da linguagem do psicanalista”, in Escritos. São Paulo: Perspectiva.

(1972-1973/1985) O seminário. Livro 20. Mais, ainda. Rio de Janeiro: Jorge Zahar.

. (1959-1960/1988) O seminário. Livro 7. A ética da psicanálise, 1959-

1960. Rio de Janeiro: Jorge Zahar.

(1969-1970/1992) O seminário. Livro 17. O avesso da psicanálise, 1969-

1970. Rio de Janeiro: Jorge Zahar.

(1960/1998) “Subversão do sujeito e dialética do desejo", in Escritos. Rio de Janeiro: Jorge Zahar.

(2003) "Proposição de 9 de outubro de 1967 sobre o psicanalista

da Escola”, in Outros escritos. Rio de Janeiro: Jorge Zahar. 
LAIA, S. (2010). A psicanálise aplicada à terapêutica e a política da psicanálise hoje. Revista eletrônica do núcleo Shépora, v.V, n.10. Disponível em: http://www.isepol.com/asephallus/numero_10/artigo_08_revista10.html. Acesso em 15 de julho de 2011.

LE BRETON (2006). Entrevista com Le Breton. Iara Revista de Moda Cultura e Arte, v.2, n.2. Disponível em: http://www.iararevista.sp.senac.br. Acesso em 16/12/2015.

LIPOVETSKY, G. (2009) O império do efêmero. São Paulo: Cia de Bolso.

MARROUN, K. E VIEIRA, M. (2008) Corpo, uma mercadoria na pós-modernidade. Psicologia em Revista, Belo Horizonte, v.14, n.2, p.171-186, dez.

MILLER, J. (1998-1999) A experiência do real no tratamento analítico. Seminário de Jacques-Alain Miller 1998-1999. Escola Brasileira de Psicanálise, São Paulo. Tradução para uso interno.

(2011) Intuições milanesas 1. Opção Lacaniana online nova série, ano 2, no 5. Disponível em: http://www.opcaolacaniana.com.br/pdf/ numero_5/Intui\%C3\%A7\%C3\%B5es_milanesas.pdf. Acesso em $17 / 12 / 2015$.

(2012) Os seis paradigmas do gozo. Opção Lacaniana online nova série, ano 3, n.7. Disponível em: http://www.opcaolacaniana.com. br/pdf/numero_5/Intui\%C3\%A7\%C3\%B5es_milanesas.pdf. Acesso em 17/12/2015.

ORTEGA Y GASSET, J.(1961) A rebelião das massas. Rio de Janeiro: Livro Ibero-americano.

QUINET, A. (2012) As $4+1$ condições da análise. 12 ed. Rio de Janeiro: Jorge Zahar.

RECALCATI, M. (2009) A questão preliminar na época do Outro que não existe. Revista digital Latusa, ano 1, n.7. Disponível em: http://www. latusa.com.br/latmartex7_2.htm. Acesso em 17/12/2015.

ROUDINESCO, E. (2003) A família em desordem. Rio de Janeiro: Jorge Zahar. VILTARD, M. (1996) “Amor”, in: KAUFMANN, P (Ed). Dicionário enciclopédico de psicanálise. O legado de Freud e Lacan. Rio de Janeiro: Jorge Zahar.

Maria Angélica Augusto de Mello Pisetta

angelicapisetta@yahoo.com.br 
